\title{
Enlarged mouse preputial glands
}

\author{
Thomas M. Donnelly, DVM, DipACLAM ${ }^{1}$ \& James Walberg, DVM, DipACVP 2
}

A research institute maintained a small colony of aging C57Bl6 mice (older than 22 months) that had been control mice in research studies before being transferred to the aging colony.

The mice were housed either individually or in pairs in ventilated cages with corncob bedding. Room temperature was maintained at $18-26^{\circ} \mathrm{C}\left(62-79{ }^{\circ} \mathrm{F}\right)$, and humidity at $30-70 \%$. The light cycle was 12-h:12-h light:dark. Extra nesting material (Nestlets, Ancare, Bellmore, NY) was provided as environmental enrichment. Mice were fed ad libitum Purina Lab Diet Rodent Chow 5001 (Purina Mills, St. Louis, MO) and provided ad libitum access to water from a reverse osmosis system. Health surveillance for this colony consisted of testing samples taken from sentinels exposed to dirty bedding. Samples were tested at least twice annually. The colony was serologically negative for murine microbial pathogens (mouse parvovirus, mouse minute virus, mouse hepatitis virus, Theiler's encephalitis virus, mouse rotavirus, Sendai virus, pneumonia virus of mice, reovirus type 3 , lymphocytic choriomeningitis virus, mouse adenoviruses, ectromelia virus, K virus, polyoma virus, Mycoplasma pulmonis and Clostridium piliforme) and negative for mites and pinworms (as determined by direct examination).

During a 12 -month period, animal technicians had reported ventral subcutaneous lumps in 24 male mice from this colony. The lumps were bilaterally symmetrical or, occasionally, unilateral. Clinical examination of two mice identified non-painful, ovoid, subcutaneous lumps of
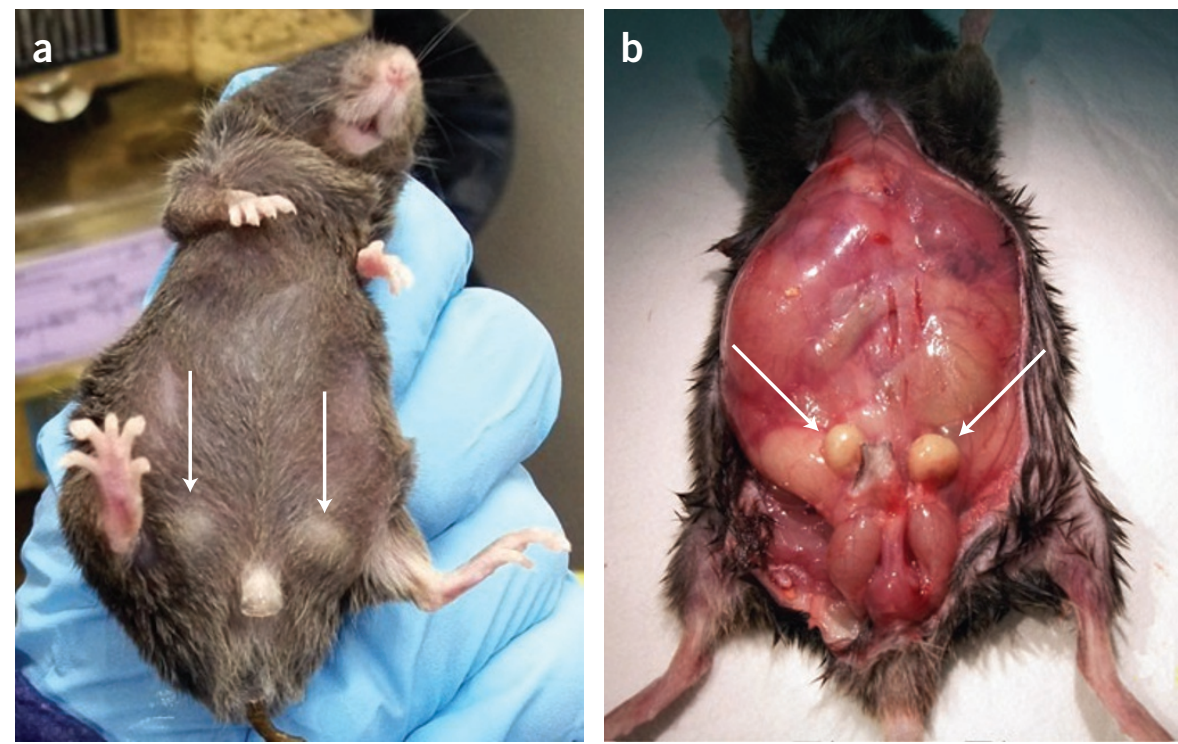

FIGURE 1 | The ventral aspect of a 23-month-old male C57Bl6 mouse. (a) Bilateral subcutaneous swellings (arrows). (b) At necropsy, the ventral skin has been peeled back, revealing the thin abdominal musculature and enlarged preputial glands (arrows) corresponding to the subcutaneous swellings that were visible externally.

$0.4-0.5 \mathrm{~cm}$ in diameter on either side of the penis (Fig. 1a). Affected mice maintained normal weight and activity. In a few mice, the lumps ruptured and the skin over the lesion ulcerated. A third mouse with a ruptured lump was examined, and a skin ulcer about $0.9 \mathrm{~cm} \times 0.4 \mathrm{~cm}$ in size was observed adjacent to the penis.

The mice were diagnosed as having enlarged preputial glands. In some cases, the glands became so large that they ruptured, causing skin ulceration. To investigate the cause of the enlarged preputial glands, two affected mice were euthanized by carbon dioxide asphyxiation. One mouse had enlarged preputial glands that measured $0.5 \mathrm{~cm} \times$ $0.2 \mathrm{~cm} \times 0.2 \mathrm{~cm}$ and $0.4 \mathrm{~cm} \times 0.3 \mathrm{~cm} \times$ $0.2 \mathrm{~cm}$ after dissection (Fig. 1b). The other mouse had a ruptured preputial gland. The dissected enlarged glands and the haired skin and subcutaneous tissue surrounding the ruptured gland were fixed in $10 \%$ neutral buffered formalin and submitted for histopathology analysis.

What do you think is the cause of the enlarged preputial glands from the aging C57Bl6 male mice? Are the glands hypertrophic, neoplastic or infected?

\section{What's your diagnosis?}

